\title{
BRACKISH WATER DESALINATION USING REVERSE OSMOSIS SYSTEM
}

\author{
K. I. Wasfy ${ }^{1}$
}

\section{ABSTRACT}

Desalination technologies of brackish water have become a great concern. Reverse osmosis (RO) membranes are the leading technology for desalination because of their strong separation capabilities and a great potential for treatment of waters worldwide. Performance evaluation of RO for brackish water desalination was studied under Four feed pressures (20, 25, 30 and 35 bar), Five levels of water salinity (1200, 5000, 10000, 15000 and $20000 \mathrm{ppm}$ ) and number of RO membranes (two and three stages). RO system evaluation was carried out in terms of water quantity and quality according to World Health Organization guidelines.

The major results could be summarized as follow: -

- Increasing feed pressure, increased salt rejection and permeate flux, while the permeate salinity and specific energy was decreased.

- Increasing feed water salinity, decreased the permeate flux, while the salt rejection was increased up to 5000 and then decreased.

- Using three RO membranes were sufficient to give the required quality water specification and lower specific energy consumption.

- For household and agricultural uses: Operate RO desalination system under 20 bar pressure for 1200, 5000 and 10000 ppm water salinity, while use 25 bar for 15000 ppm and 30 bar for 20000 ppm salinity.

- For industrial uses (Hatching): Operate RO desalination system under 35 bar pressure for 1200 ppm water salinity to obtain the desired limits of water quality for disinfection (5-10 ppm).

Keywords: Brackish water, Reverse osmosis, Desalination, Operating parameters, Water quality

\section{INTRODUCTION}

W ater is an abundant natural resource that covers three quarters of the earth's surface. Water shortage is expected to be one of the biggest problems facing the world.

\section{${ }^{1}$ Lecturer of Agric. Eng., Fac. of Agric., Zagazig Univ.}




\section{Nomenclature}

RO Reverse Osmosis

TDS Total Dissolved Solids

$\boldsymbol{B} \boldsymbol{W}$ Brackish water

$\boldsymbol{J}_{\boldsymbol{v}} \quad$ Permeate flux

$\boldsymbol{A}_{\boldsymbol{c}}$ Membrane area

$\boldsymbol{Q}_{\boldsymbol{p}} \quad$ Permeate flow rate

$\boldsymbol{R} \quad$ Salt rejection

$\boldsymbol{C}_{\boldsymbol{f}} \quad$ Feed concentration

BWRO Brackish water Reverse Osmosis

$\boldsymbol{C}_{\boldsymbol{p}}$ Permeate concentration

$\boldsymbol{C}_{\boldsymbol{a}}$ Average feed concentration

$\boldsymbol{C}_{\boldsymbol{c}}$ Concentrate concentration

SEC Specific Energy Consumption

According to the Worldwatch Institute, more than two-thirds of the world's population may experience water shortages at 2025, thus affecting practically every country in the world. Therefore, there is a need to use desalination technologies, which can play a large role in supplying fresh water to areas that have access to BW and be the solution for these scarcity problems. Desalination is the process of removing salt from water to produce fresh water (less than $1000 \mathrm{ppm}$ of salts) (Sandia, 2003). This is compatible with World Health Organization guideline of TDS levels are that the water palatability with a TDS level of less than about 600 ppm is generally considered to be good quality drinking water; while drinking-water becomes significantly and increasingly unpalatable at TDS levels greater than about $1000 \mathrm{ppm}$. The feed water salinity for desalination ranges from approximately $1000 \mathrm{ppm}$ TDS to $60,000 \mathrm{ppm}$ TDS, although feed waters are typically labeled as one of two types: seawater or BW. Although most seawater sources contain 30,000-45,000 ppm TDS, seawater RO membranes are used to treat waters within the TDS range $10.000-60.000 \mathrm{ppm}$. BWRO membranes are used to treat water sources (often groundwater sources) within a range of 1000-10.000 ppm TDS (Mickley, 2001). Miranda and Infield (2002) stated that it is very important to operate RO under broad operational Windows. The main thresholds of the operational window include the maximum feed pressure (determined by the membrane mechanical resistance); maximum brine flow rate (should not be exceeded to avoid membrane deterioration); minimum brine flow rate (should be maintained to avoid precipitation and consequent membrane fouling); and maximum product concentration (if the applied pressure is less than a determined value, the 
permeate concentration will be too high). Greenlee et al. (2009) stated that RO membrane technology are the leading technology for new desalination installations, and they are applied to a variety of salt water resources using tailored pretreatment and membrane system design. Two distinct branches of RO desalination have emerged: seawater RO and BWRO. Differences between the two water sources, including foulants, salinity, waste brine (concentrate) disposal options, and plant location, have created significant differences in process development, implementation, and key technical problems. Al-Karaghouli and Kazmerski (2012) proved that RO is the most reliable, cost effective and energy efficient in producing fresh water compared to other desalination technologies. It is the fastest growing desalination technology with a greater number of installations around the world. Qiu and Davies (2012) mentioned that BWRO desalination is still subject to intensive energy consumption compared to the theoretical minimum energy demand. SEC reduction of BWRO can be achieved by (i) increasing number of stages, (ii) using an energy recovery device (ERD), or (iii) operating the BWRO in batch mode or closed-circuit mode. Application of more stages not only reduces SEC but also improves water recovery. However, this improvement is less pronounced when the number of stages exceeds four. A further reduction of about $30 \%$ in SEC can be achieved through batch RO operation. Alghoul et al. (2016) constructed RO units using a modular approach; this would allow them to adapt to a renewable power supply. Small-scale PV-RO would be a promising form of desalination system in remote areas, where BW is more common. They quantified the effect of climatic design operation conditions on the performance and durability of a PV-BWRO desalination system. The design was limited to a $2 \mathrm{kWp}$ PV power system, five different membranes, a feed TDS of $2000 \mathrm{ppm}$ and a permeate TDS of less than $50 \mathrm{ppm}$. The results showed that the optimum RO load, membrane type, and design configuration were $600 \mathrm{~W},(4 " x 40 "$ TW30-4040), and a two-stage configuration, respectively. Operating the PV-BWRO system for $10 \mathrm{~h}$ during the day would produce $5.1 \mathrm{~m}^{3}$ of fresh water at a specific energy of $1.1 \mathrm{kWh} / \mathrm{m}^{3}$. Kotb et al. (2016) implemented a simple approach to identify the optimum RO system structure and the operating parameters leading to the 
minimum total cost. Various two-stage and three-stage arrangements of practical functionality have been optimized to find the minimum cost. The minimum overall costs per unit permeate for the single, two and threestage arrangements are $1.41,1.00$ and $0.91 \$ / \mathrm{m}^{3}$, respectively at product rates of $5.5,11.5$ and $17 \mathrm{~m}^{3} / \mathrm{h}$. For two-stage systems, parallel arrangement is recommended for production up to $3 \mathrm{~m}^{3} / \mathrm{h}$. Series arrangement with feed and retentate bypass is recommended for demands between 3 and $9 \mathrm{~m}^{3} / \mathrm{h}$. For higher permeate rates, series arrangement is recommended. Imbrogno et al. (2017) indicated that due to a significant drop in the energy needed for RO desalination from $12 \mathrm{kWh} / \mathrm{m}^{3}$ to $\sim 2 \mathrm{kWh} / \mathrm{m}^{3}$ over the past 20 years, which is close to the theoretical minimum for recovering salt free water from seawater of $1 \mathrm{kWh} / \mathrm{m}^{3}$, the focus is on the critical aspects that offer opportunities to further reduce costs. These include pre- and post-treatment; analysis and optimization of the performance of RO systems, such as selectivity, capacity and flux decline. Khanzada et al. (2017) stated that integration of renewable energy with desalination technologies has emerged as an attractive solution to augment fresh water supply sustainably. For BW treatment, pretreatment of RO feed water is a key step in designing RO plants avoiding membrane fouling. They compared at pilot scale the rejection efficiency of RO membranes with multiple pre-treatment options at different water recoveries $(30,35,40,45$ and 50\%) and TDS concentrations $(3500,4000$, and $4500 \mathrm{ppm})$. It was revealed that FO membrane with $0.25 \mathrm{M} \mathrm{MgCl}_{2}$ used as a draw solution (DS) and Ultrafiltration (UF) membrane followed by Filmtec membrane gave overall 98\% rejection but UF facing high fouling potential due to high applied pressure. Use of 5 and $1 \mu \mathrm{m}$ cartridge filter prior to Filmtec membrane also showed effective results with $95 \%$ salt rejection.

So, the main goal of this research is to study the effect of different parameters on the RO performance for treating $\mathrm{BW}$ in terms of water quantity and quality to be used either for household (drinking) or in agricultural and industrial uses (hatching as an example).

\section{MATERIALS AND METHODS}

Experiments were carried out at Poultry Company, El-Salheya El-Gedida ( $30^{\circ} 39^{\prime} 17^{\prime \prime}$ latitude and $31^{\circ} 52^{\prime} 24^{\prime \prime}$ longitude), Sharqia Governorate, 
Egypt in order to produce desalinated water for multi purposes.

\section{Materials}

\subsection{Water source}

Brackish feed water under study was used at different levels of salinity. The salinity of water was taken under consideration as an important parameter for operating RO and it was measured by TDS meter hold (Multi digital meter). The saline water was pulled from water tank $(100 \mathrm{~L}$ volume) and pushed to the following desalination unit by water motor pump of $2.5 \mathrm{hp}$ (HW-100 model, $\mathrm{Q}_{\max }$ of $172 \mathrm{~L} / \mathrm{min}, 39 \mathrm{~m}$ head, 2800 rpm and $220 \mathrm{~V}$ ).

\subsection{Desalination system}

The used desalination unit from water supply to RO membrane was represented schematically as shown in Fig 1.

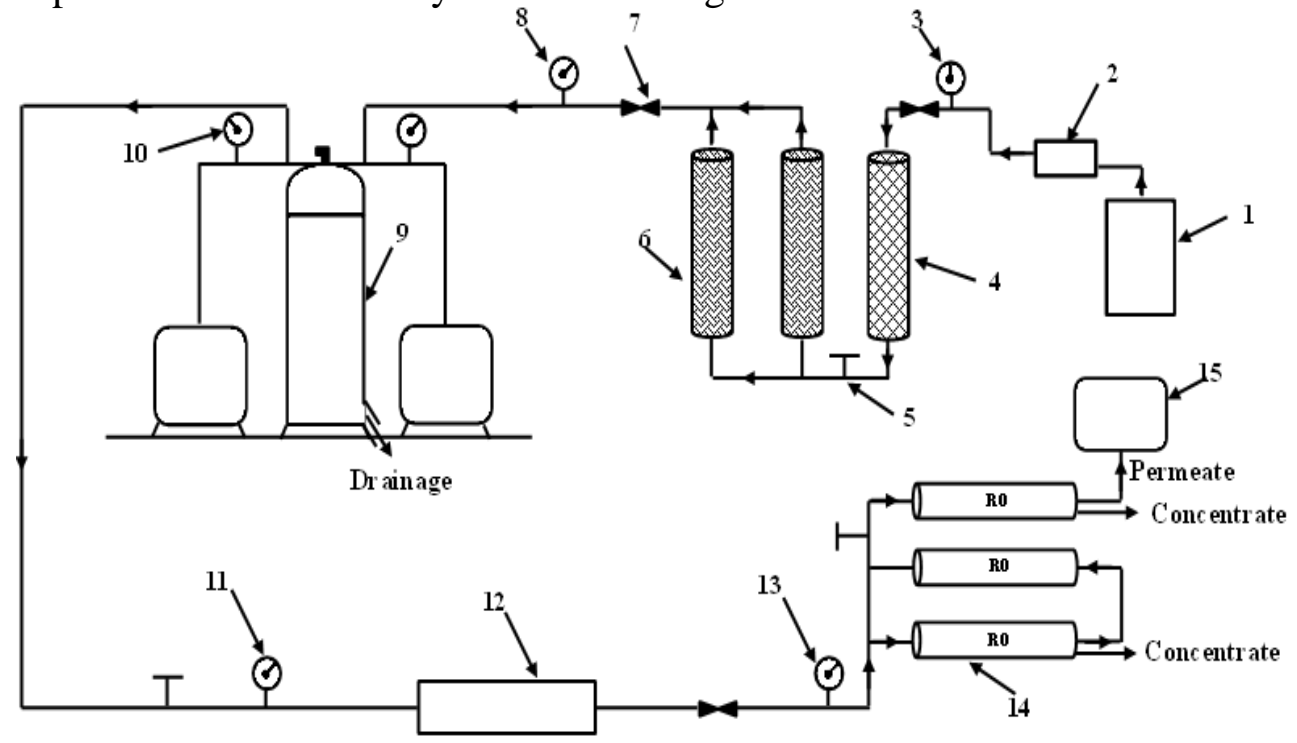

1. Feed water tank

3. Pressure gauge $(0-10$ bar $)$

5. Hand valve

7. Safety valve (Open at 3 bar pressure)

9. Chemical processing unit

11. Pressure gauge $(0-20$ bar $)$

13. Pressure gauge $(0-40$ bar $)$

15. Water storage tank
2. Water motor

4. Coarse filter

6. Fine filter

8. Pressure gauge $(0-20$ bar $)$

10. Pressure gauge $(0-15$ bar $)$

12. Pressure unit (Booster pumps)

14. RO membrane unit

\section{Fig. 1. Diagram of the used desalination system}


It was consisted of pre-treatment unit, post-treatment unit, high pressure pump and RO desalination unit as follow:

\section{- Pre-treatment unit}

Feed pre-treatment was passed on three multimedia filters (one coarse filter and double fine filters) to remove particles. Coarse filter membrane was $60 \mathrm{~cm}$ length, $6 \mathrm{~cm}$ diameter and $20 \mu$ holes diameters, while fine membranes was ranged from 10 to $0.5 \mu$ holes diameters (Americanmade) for preventing the subsequent stages of serious damage. The filter casing of these membranes was $65 \mathrm{~cm}$ length and $12 \mathrm{~cm}$ inner diameter. Before entering water to this unit, there is pressure gauge to determine the pressure and safety valve that opened when the pressure was reached to 3 bars. There is a control valve between filters to open and close when changing the filters or cleaning units. After this unit, there is a safety valve that opens at 5 bar pressure.

\section{- Post-treatment unit (Adjustment unit)}

This unit was worked to reset the physical and chemical properties of water. $\mathrm{pH}$ was adjusted to be from 5 to 7.5. Possible to add some dosing of chemical materials to get rid of iron and Manganese elements (especially, the percentage of these elements from analysis of raw feed water samples was $0.02 \%$ ) and adjust the chlorine percentage in water for drinking water production. At the top of adjustment unit, hand valve is used to control the water passing or not to the following unit at washing (open half an hour to clean the unit and discharge the water from lower hole before desalination start). On both sides of the unit, there are two pressure gauges to determine the inside and outside pressure.

\section{- High pressure pump (Reverse running pump)}

At this stage, use pumps capable of generating high enough pressure to pass clean water through the membrane and reserve the salt. There were two installed pumps on consecutive. The first pump was low pressure that pulled the water and pushed it to the other pump, it was operated by motor power of $0.75 \mathrm{hp}$. Second pump was high pressure, operated by motor of $2.5 \mathrm{hp}$ (HW-200 model, centrifugal pump, $450 \mathrm{~m}$ head, $\mathrm{Q}_{\max }$ of $180 \mathrm{~L} / \mathrm{min}$ and $3000 \mathrm{rpm}$ ). There is a valve on the high pressure pump to control the water discharge and pressure to the RO unit. The low pressure switch $(0-20$ bar) was installed on the iterance of this unit $(0.14$ bar 
shutdown and start at 0.21 bar) at in order to stop the pump work at low water pressure for any reasons (water outage or low level of feed flow rate). However, the other switch of high pressure $(0-40)$ was at outlet of this unit to stop the pump work at the highest pressure as a result of water storage tank is full, before this switch the safety valve was put (open at 40 bar pressure).

\section{- Reverse Osmosis unit (Treatment unit)}

$\mathrm{RO}$ is a pressure driven membrane process that uses the osmosis phenomenon. Water will pass through the spiral wound module membrane (50 cm length, $7 \mathrm{~cm}$ diameter and $A_{c}$ of $340 \mathrm{~cm}^{2}$ ), when the applied pressure is higher than the osmotic pressure, while salt is retained. There were two and three stages of RO membranes (the first was installed with the second on consecutive but the third is parallel). The dimension of RO membrane casing was $55 \mathrm{~cm}$ length and $12.5 \mathrm{~cm}$ inner diameter). The polymer material of membranes forms a layered and water must follow a tortuous pathway through the membrane to reach the permeate side. This is an important and costly unit in desalination process. The feed water was passed through the previous pretreatments units to protect the osmosis unit life from contaminants that prevent its operation efficiently and may cause disruptions. The permeate water that delivered from RO unit is received in storage tank, while the concentrate water was collected to desalinate it again.

\section{Methods}

Desalination BW using RO unit was done under the following methodology:

\subsection{Experimental methodology}

Experiments of water desalination were carried out under different parameters of:

- Number of RO membrane stages (Two and three stages)

- Five levels of feed water salinity (1200, 5000, 10000, 15000 and 20000 ppm)

- Four different values of RO pressure (20, 25, 30 and 35 bar)

\subsection{Measurements}

The performance of RO membrane was evaluated according to LANXESS Deutschland Gmbh (2013) as below: 


\subsubsection{Water quantity}

The water quantity was measured through:

\section{- Flow Rate}

Flow rate $\left(\mathrm{m}^{3} / \mathrm{h}\right)$ is the rate of water that entering the RO system. In RO device there are three streams, the feed stream $\left(10.80 \mathrm{~m}^{3} / \mathrm{h}\right)$ is separated by RO membrane into permeate and concentrate streams. Permeate flow rate is the rate of water passing through the RO membrane, while concentrate flow rate is the rate of flow which has not passed through the RO membrane and comes out from the RO system with rejected ions.

\section{- Permeate flux}

$J_{v}$ is the quantity of permeate produced during membrane separation per unit of time and RO membrane area. It is defined by: $J v=Q_{P} / A_{c}$

\subsubsection{Water quality}

The water quality from RO unit was determined as follow for:

\section{- Permeate water salinity}

It was measured by TDS meter after each treatment.

\section{- Salt rejection}

Salt rejection is a percentage which describes the amount of solute retained by the $\mathrm{RO}$ membrane. The retention is given by:

$R=\left[1-\left(C_{p} / C_{a v}\right)\right] \times 100$

$C_{a v}=\left(C_{f}+C_{c}\right) / 2$

\subsubsection{Specific energy consumption}

It was calculated according to the following formula:

$S E C=$ Required power $/$ permeate flow rate

The required power was estimated according to (Kurt, 1979):

$P=(\sqrt{3} \times \cos \varphi \times I \times V) / 1000$

Where, $P$ : Required power, $\mathrm{kW} ; \cos \varphi=0.7$; I: Current intensity, Ampere and $V$ : Voltage $(380 \mathrm{~V})$.

\section{RESULTS AND DISCUSSION}

The obtained data from performance evaluation of BWRO will be discussed under the following topics:

\section{Permeate water salinity}

Permeate water salinity under different parameters was illustrated in Fig. 2. 


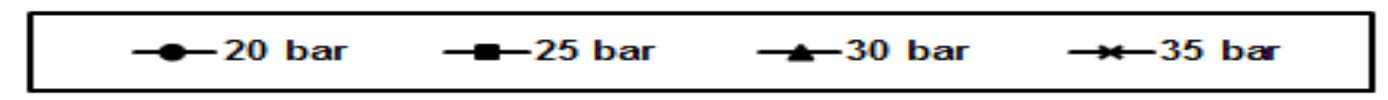

Two membrane stages

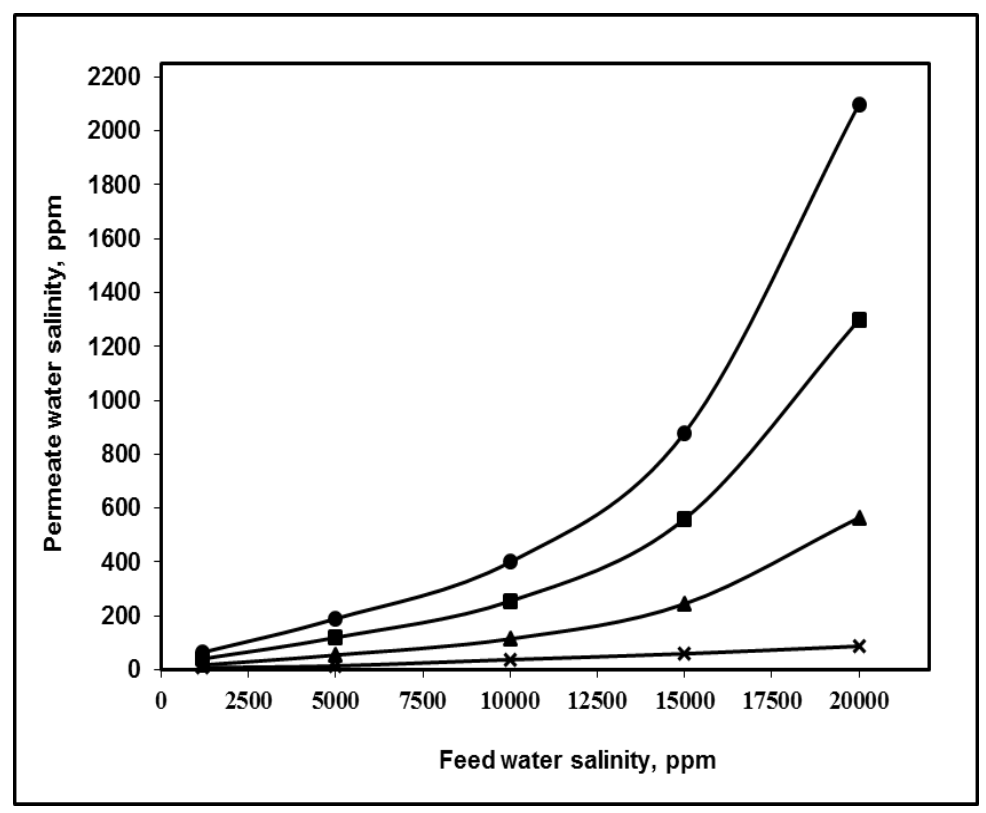

Three membrane stages

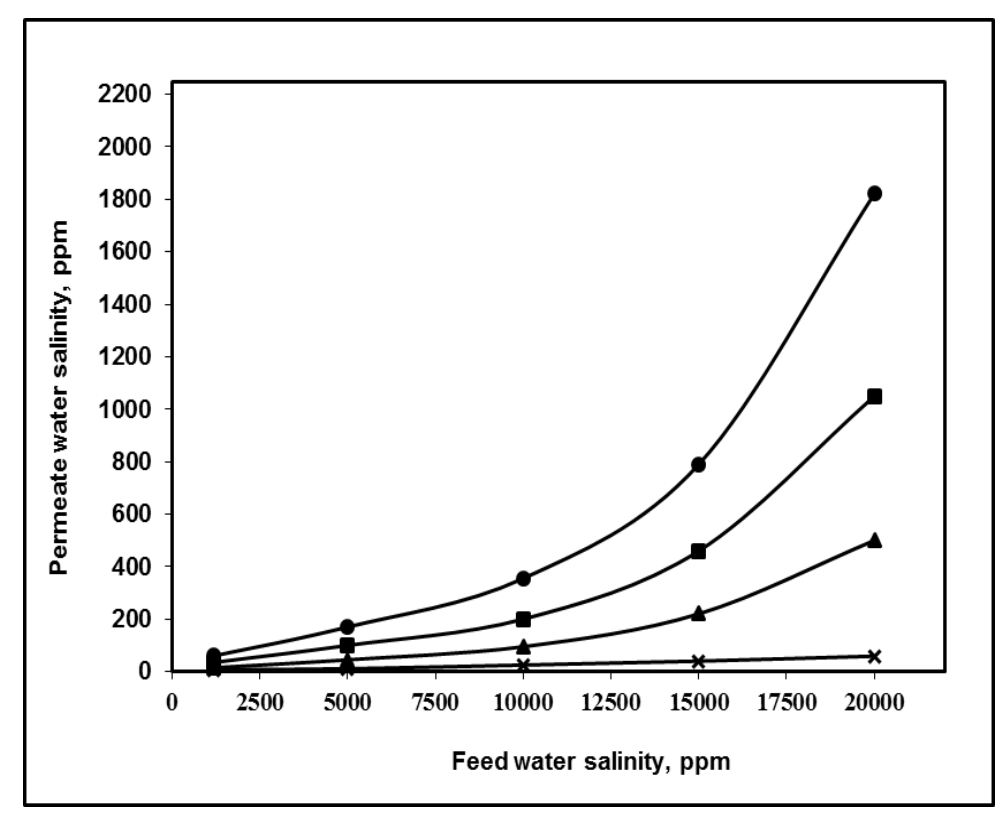

Fig. 2. Effect of different parameters on permeate water salinity 
Results indicated that permeate salinity was increased by increasing feed salinity. It was decreased from 1200, 5000, 10000, 15000 and 20000 ppm to $18,55,115,245$ and $565 \mathrm{ppm}$, respectively under 35 bar pressure and two RO membranes.

Regarding to the effect of RO pressure, it was clarified that the water salinity was decreased by increasing pressure. This is due to high pressure force of water to flow; the solute is retained by the membrane. At the highest BW salinity of 20000 and two RO membranes, the salinity values were 2100, 1300, 565 and 88 ppm for 20, 25, 30 and 35 bar, in that order. With respect to number of membrane stages, the permeate water salinity by using two RO membranes was 400, 255, 115 and 38 ppm under 20, 25, 30 and 35 bar for $10000 \mathrm{ppm}$. While, it was reduced to 355, 200, 95 and 25 ppm under the previous conditions, respectively by using three number membranes desalination. Three stages of RO membrane reduced the permeate salinity than two RO membrane, however the change between them were not clearly noticeable.

\section{Permeate flux}

Effect of different water salinity levels, feed pressure and number of membrane stages on permeate flux was illustrated in Fig. 3.

The obtained data of permeate flux under variation of water salinity revealed that the permeate flux was decreased by increasing feed water salinity at constant pressure. Increasing the salt concentration in feed water, decrease the recovery rate, the salt caused a hindrance to pass the water through semi-permeable membrane and thus, the permeate flux was decreased. The flux values were $84.71,78.35,68.82,55.06$ and 36 $\mathrm{m}^{3} / \mathrm{h} . \mathrm{m}^{2}$ at water salinity values of $1200,5000,10000,15000$ and 20000 ppm, respectively under 25 bar and pass the water through three RO membranes.

Concerning the effect of different feed pressures of 20, 25, 30 and 35 bar, the permeate flux increases with increasing transmembrane pressure. This is due to increase in net driving force (difference between feed pressure and osmotic pressure), the recovery of a RO unit increases and thus the permeate flux is increased. This is compatible with Greenlee, et al. (2009). Values were $111.18,117.53,127.06$ and $136.59 \mathrm{~m}^{3} / \mathrm{h} . \mathrm{m}^{2}$ under $1200 \mathrm{ppm}$ water salinity and previously mentioned pressures for two membrane stages, respectively. 


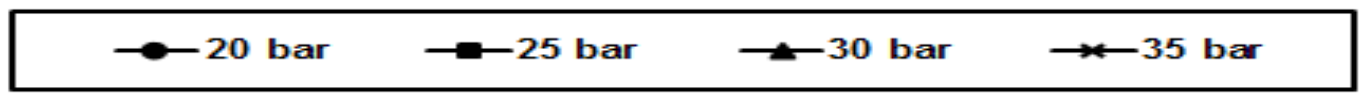

Two membrane stages

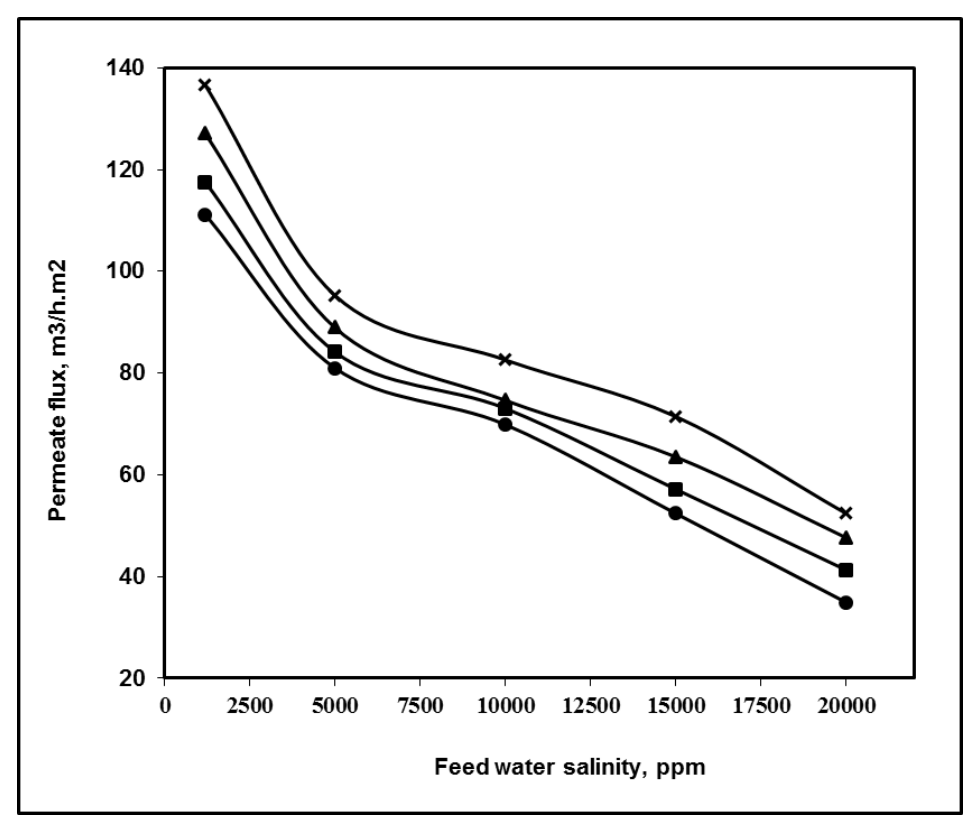

Three membrane stages

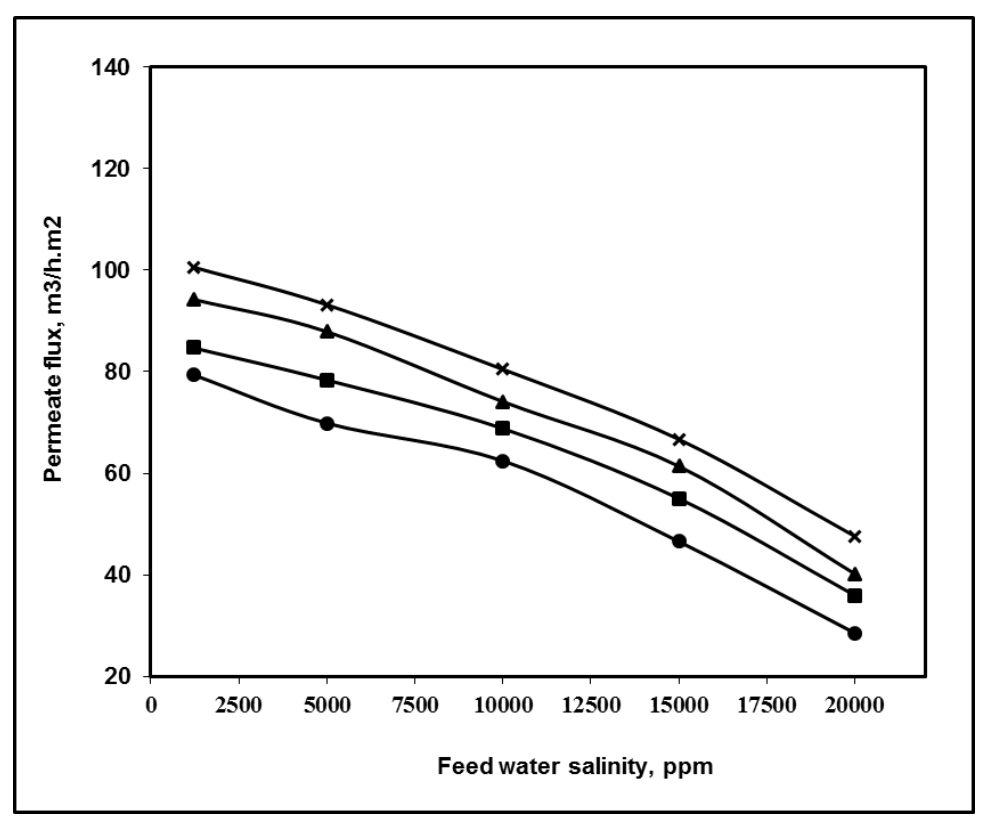

Fig. 3. Permeate flux under different operating parameters 
By the use of three RO membranes, the permeate flux was decreased under the same pressure, salinity and consumed time comparing with two membranes. At 30 bar pressure, the flux was 127.06, 88.94, 74.65, 63.53 and $47.65 \mathrm{~m}^{3} / \mathrm{h} . \mathrm{m}^{2}$ for two stages, while $94.24,87.88,74.12,61.41$ and $40.24 \mathrm{~m}^{3} / \mathrm{h} . \mathrm{m}^{2}$ for three RO stages under 1200, 5000, 10000, 150000 and $20000 \mathrm{ppm}$, in that order. At three membranes, the permeate flow rate was increased, but the rate of this increment to membranes area was decreased compared to two RO stages.

\section{Salt rejection}

Salt rejection is an important indication to water quality. Effect of different parameters on the rejection percentage was shown in Fig. 4.

Results indicated that the highest percentage of salt rejection was reached in the average feed salinity range of 1200 to $5000 \mathrm{ppm}$. Afterwards, the salt rejection decreased as the feed concentration increased. It was 94.58 , $96.20,96,94.13$ and $89.50 \%$ for two membrane stages, while it was 95 , $96.60,96.45,94.73$ and $90.90 \%$ for three membrane stages under conditions of 1200, 5000, 10000 and 15000 and 20000 ppm water salinity and 20 bar pressure. The salt rejection was decreased due to charged effect of RO membrane.

In RO process, the rejected brine effluent will be having high pressure and having a considerable percentage of feed pressure. The rejection percentage was increased by increasing feed pressure.

This is agreement with Greenlee et al., (2009). At 5000 ppm salinity, the rejection values were $96.20,97.60,98.90$ and pressure of $99.72 \%$ under 20, 25, 30 and 35 bar and by the use of two RO membranes.

With respect to use two and three RO stages to desalinate the brackish water, results indicated that the percentage of salt rejection was increased under using three RO membranes due to multi-effect of increasing number of membranes on reducing the salt concentration of permeate water and thus, the efficiency of RO unit for removing salt was increased and the increasing the salt rejection comparing with two RO membranes unit.

\section{Specific energy consumption}

Specific energy consumption under different operating parameters of water salinity, feed pressure and RO stages was illustrated in Fig. 5. 


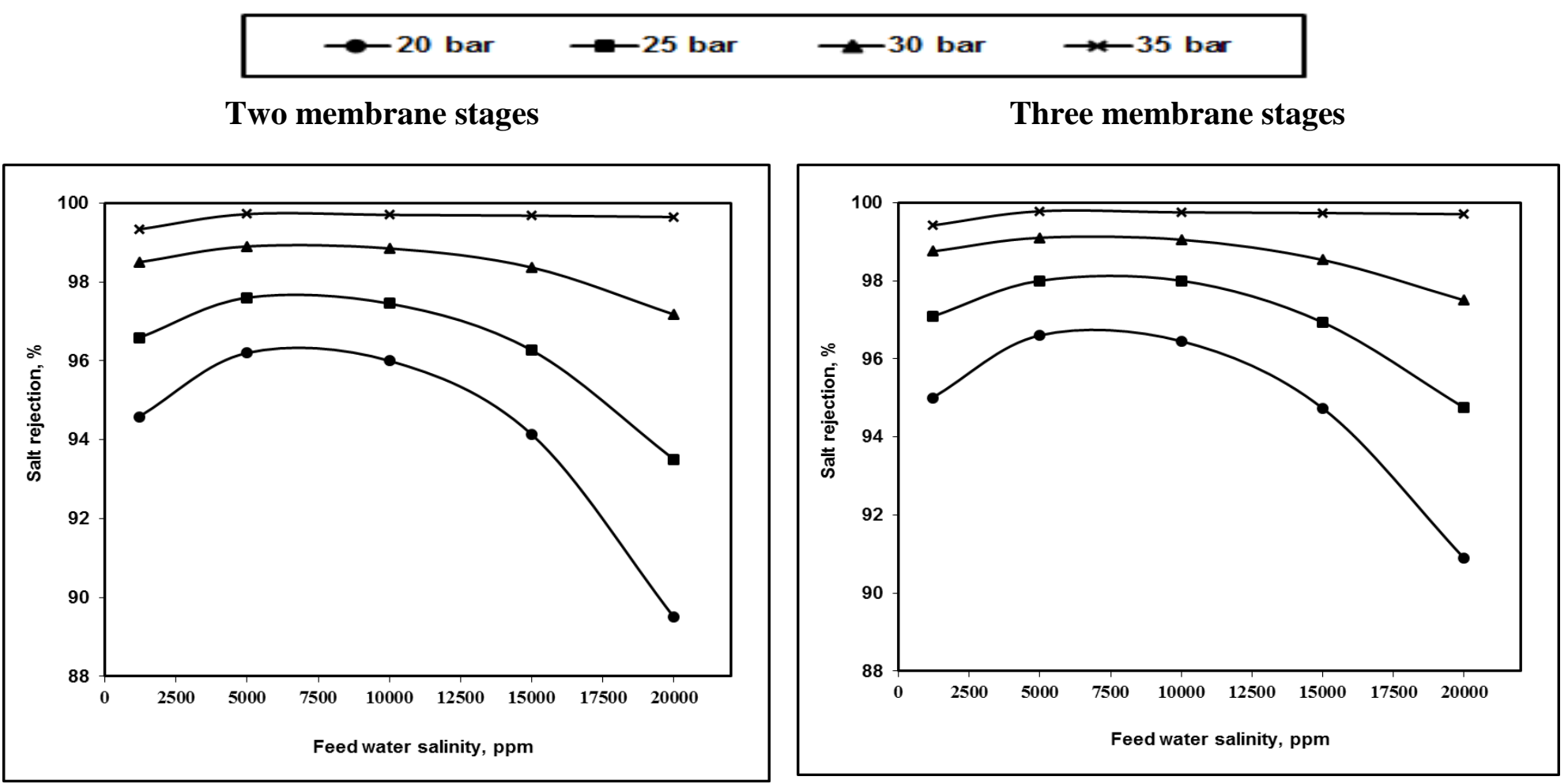

Fig. 4. Variation of salinity rejection percentage under feed water salinity, feed pressure and number of RO membrane stages 
With regard to the effect of feed water concentrations, results indicated that SEC was increased by increasing the feed water concentration. It was $0.23,0.26,0.29,0.39$ and $0.63 \mathrm{~kW} . \mathrm{h} / \mathrm{m}^{3}$ for water salinity of 1200,5000 , 10000, 15000 and $20000 \mathrm{ppm}$, respectively under using three membranes and 20 bar RO pressure. This may be due to permeate flow rate was decreased by increasing water salinity and thereby, SEC was increased.

Respecting to feed pressure treatments, it was noticed that the permeate flow rate was increased by increasing RO pressure and so, SEC was decreased. The values of treating water salinity of $15000 \mathrm{ppm}$ by passing through two membranes were $0.52,0.47,0.43$ and $038 \mathrm{~kW} . \mathrm{h} / \mathrm{m}^{3}$ for 20 , 25, 30 and 35 bar, in that order.

By the use of three RO membranes, SEC was decreased comparing with two membranes stages. Because of increasing the permeate flow rate by the use of three membranes, which leading to decrease the SEC. For two membranes, it was consumed to $0.39,0.37,0.36$ and $0.33 \mathrm{~kW} . \mathrm{h} / \mathrm{m}^{3}$, while $0.29,0.26,0.24$ and $0.22 \mathrm{~kW} . \mathrm{h} / \mathrm{m}^{3}$ for three RO membranes under 10000 ppm water salinity and feed pressure of $20,25,30$ and 35 bar, respectively. Increasing number of membranes stages, SEC was reduced for BWRO. This is agreement with Qiu and Davies (2012).

\section{CONCLUSION}

The conclusions of the study can be summarized:

- Using three RO membranes were sufficient to give the required quality water and lower SEC.

- For household and agricultural uses; operate RO desalination system under 20 bar pressure for 1200, 5000 and 10000 ppm water salinity, 25 bar for 15000 ppm and 30 bar for 20000 ppm.

- For industrial uses (Hatching); operate RO desalination system was under 35 bar pressure for $1200 \mathrm{ppm}$ water salinity to obtain the desired limits of water quality for egg disinfection (5 - $10 \mathrm{ppm})$.

The author's future work of research will be extended to integrate renewable energy with RO or with other desalination systems for enhancing product quality, reducing membrane fouling and energy consumption for desalination. 


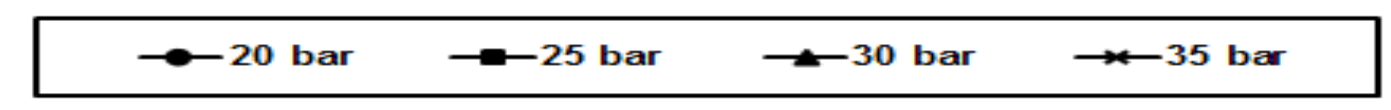

Two membrane stages

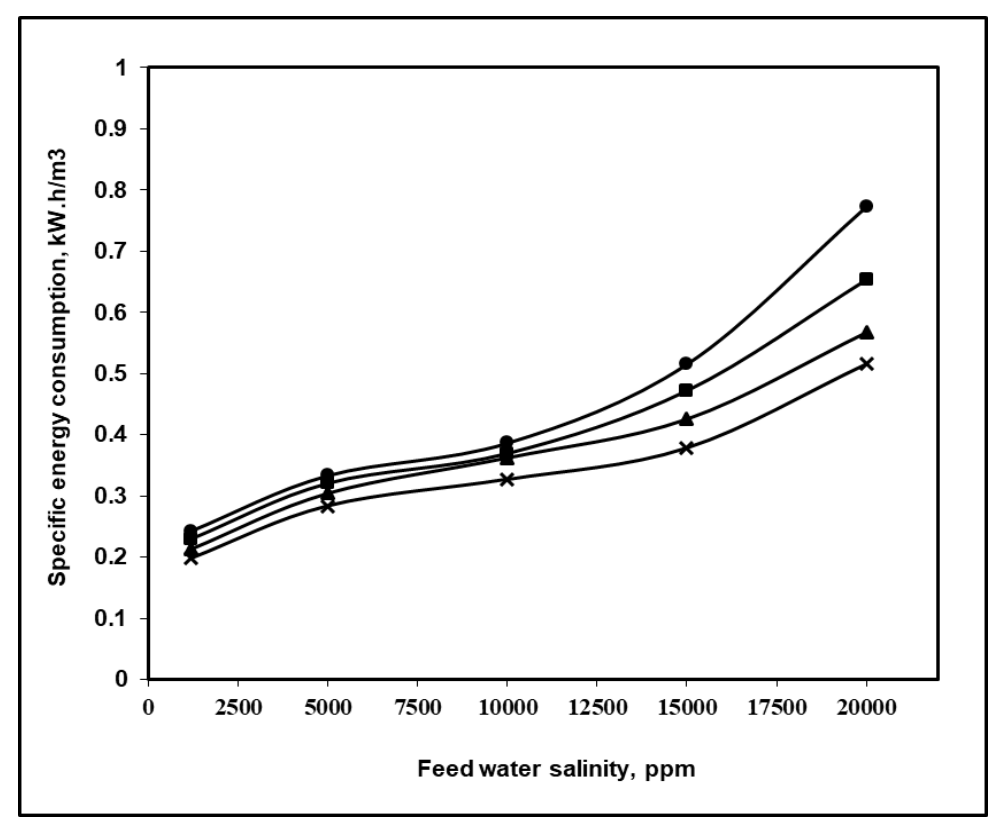

Three membrane stages

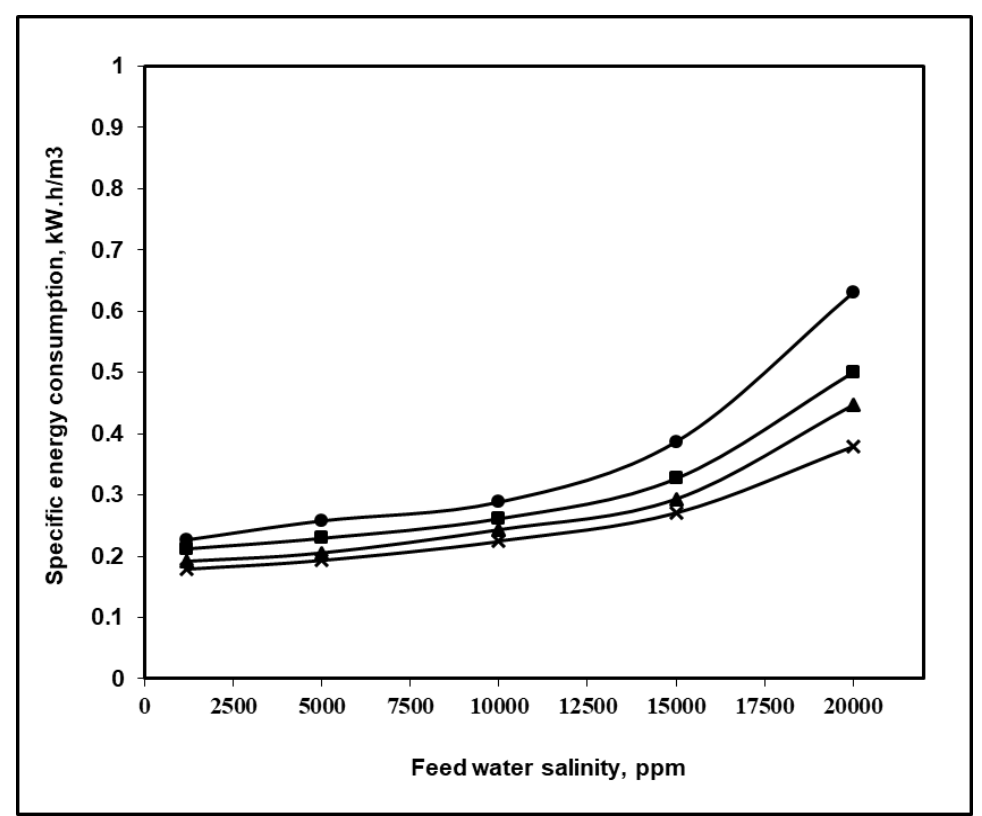

Fig. 5. Effect of feed water salinity, pressure and RO membrane stages on specific energy consumption 


\section{REFERENCES}

Alghoul, M. A; P. Poovanaesvaran, M. H. Mohammed, A. M. Fadhil, A. F. Muftah, M. M. Alkilani and K. Sopian (2016). Design and experimental performance of brackish water reverse osmosis desalination unit powered by $2 \mathrm{~kW}$ photovoltaic system, Renewable Energy, 93: $101-114$.

Al-Karaghouli, A. and L. Kazmerski (2012). Economic and technical analysis of a reverse-osmosis water desalination plant using Deep3.2 Software, J. of Environmental Science and Engineering, 1(3A): 318.

Greenlee, L. F; D. F. Lawler, B. D. Freemaa, B. Marrot and P. Moulin (2009). Reverse osmosis desalination: Water sources, technology and today's challenges, Water Research, 43: 2317-2348.

Imbrogno, J; J. J. Keating, J. Kilduff and G. Belfort (2017). Critical aspects of RO desalination: A combination strategy, Desalination, 401: $68-87$.

Khanzada, N. K; S. Jamal Khan and P. A. Davies (2017). Performance evaluation of reverse osmosis (RO) pre-treatment technologies for in-land brackish water treatment, Desalination, 406, 44 - 50.

Kotb, H; E. H. Amer and K. A. Ibrahim (2016). On the optimization of RO (Reverse Osmosis) system arrangements and their operating conditions, Energy, 103: 127 - 150.

Kurt, G. (1979). Engineering formulas. Third Ed. Mc Graw-Hill book Company. New York St. Lous San Francisco Montreal-Toronto.

LANXESS Deutschland GmbH (2013). Business Unit Liquid Purification Technologies. Kennedyplatz1, 50569 Köln, Germany, http://lewabrane.com

Mickley, M. C. (2001). Membrane Concentrate Disposal: Practices and Regulation. U.S. Department of the Interior, Bureau of Reclamation, Mickley \& Associates.

Miranda, M. S. and D. Infield (2002). A wind-powered seawater reverse-osmosis system without batteries, Desalination, 153: 9 - 16.

Qiu, T. and P. A. Davies (2012). Comparison of Configurations for High Recovery Inland Desalination Systems, Water, 4: 690 - 706. 
Sandia (2003). Desalination and water purification roadmap, A report of the executive committee. DWPR Program Report \#95, U.S. Department of the Interior, Bureau of Reclamation and Sandia National Laboratories.

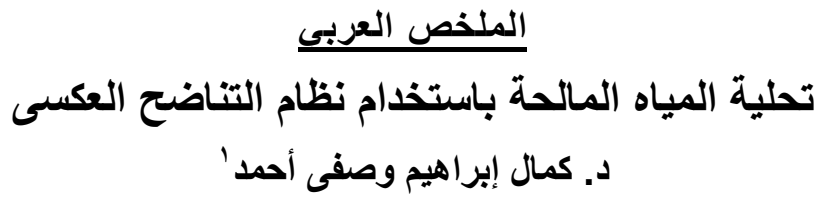

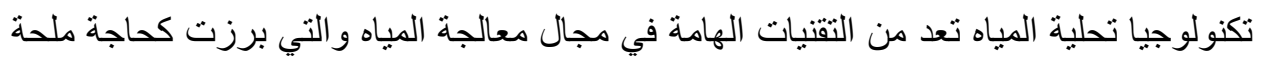

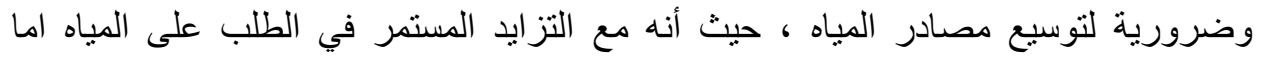

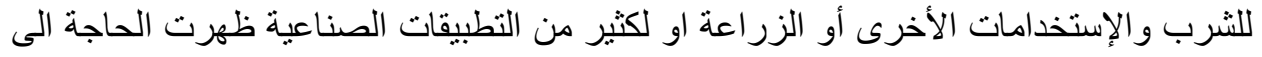

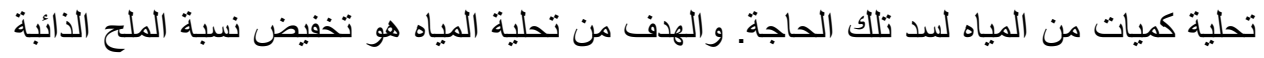

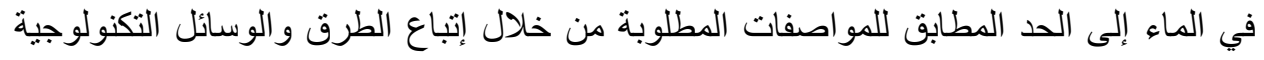

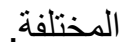

تستخدم وحدات التناضح العكسي في تطبيقات كثيرة وأهمها في تحلية مياه البحر ومياه الآبار

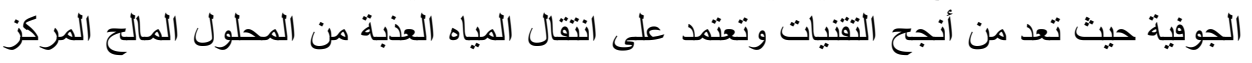

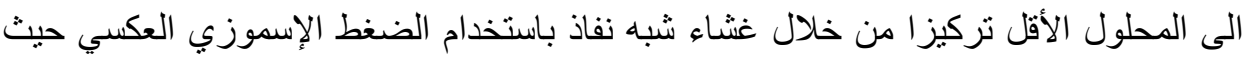

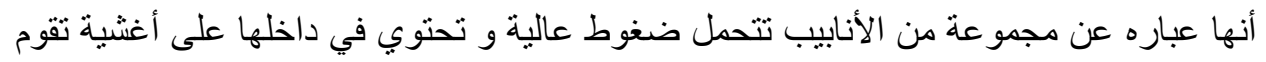
بعملية فصل ايونات المياه نتيجة للضغط عن بالبو اسطة المضخة.

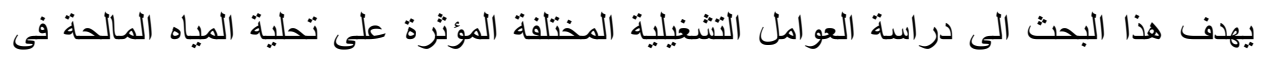

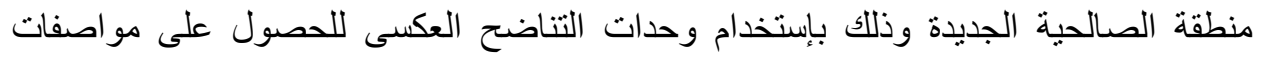

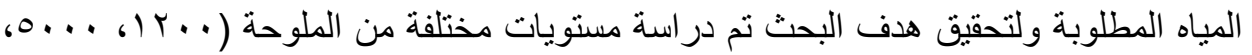

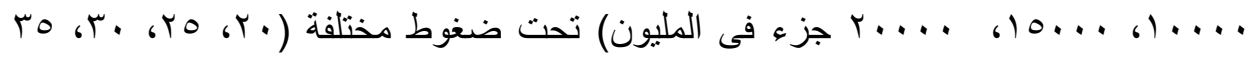

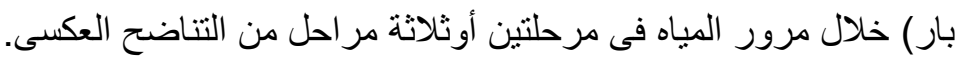

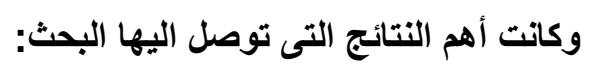

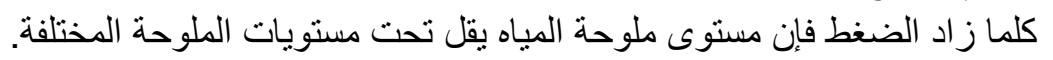

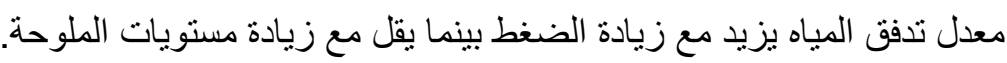

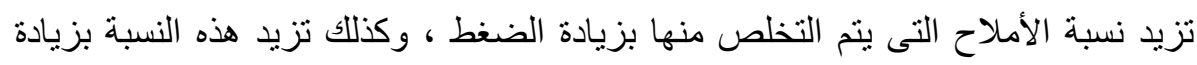

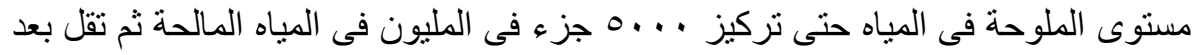

ذلك.

' مدرس بقسم الهندسة الزراعية - كلية الزراعة - جامعة الزقازيق . 
زيادة ضغط المياه يقلل من استهلاك الطاقة لنوعية فى حين أنها تزيد مع زيادة مستويات

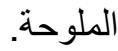
من الناحية الإقتصادية يمكن استخدام ثلاث مر احل من وحدات التناضح العكسى و التحكم فى الضغط للحصول على المستوى المطلوب من جودة المياه وتقليل الطاقة المستهلكة فى الفى الفي

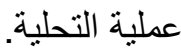

وبناءا على ذلك فإنه يوصى بالضغوط الآتية تحت مستويات الملوحة المختلفة لتناسب

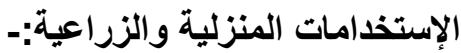

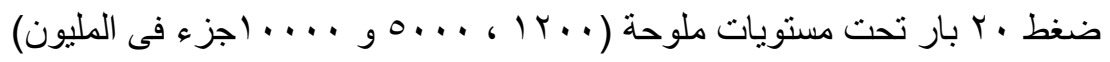

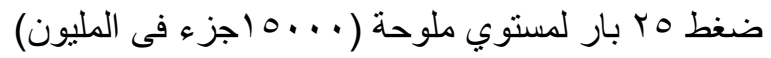

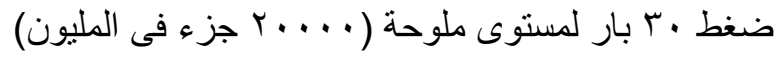
الإستخدامات الصناعية (التفريخ):-

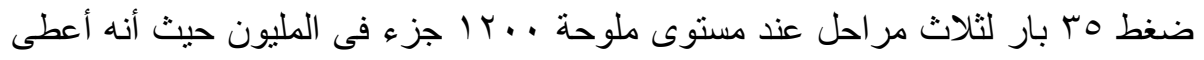

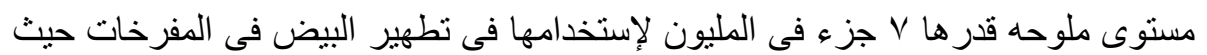

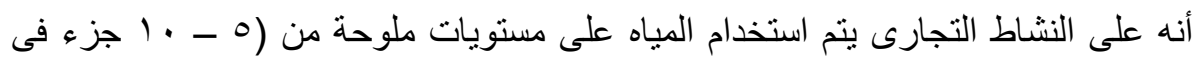
المليون)، حيث أنه وجد أن أقل من ذلك يقلل نسبة الفقس للبيض وزيادة الملوحة عن هذا المعدل يؤدى الى انسداد فتحات الرشانشات المستخدمة فى التطهير. 